\title{
Institutional Review Board Approval Date
}

National Cancer Institute

\section{Source}

National Cancer Institute. Institutional Review Board Approval Date. NCI Thesaurus.

Code C70801.

A date on which the Institutional Review Board (IRB) approved a clinical study protocol for execution at the particular institution or site. If the study receives full unconditional approval at a convened meeting, the date of IRB approval is the date of this convened meeting. If at the convened IRB meeting the study is approved subject to modifications, the date of IRB approval is the date when the requested changes are verified. 